\title{
ASPECTOS EPIDEMIOLÓGICOS DE ACIDENTES OFÍDICOS REGISTRADOS NO ESTADO DO ACRE, BRASIL, ENTRE 2013-2017: UM ESTUDO ECOLÓGICO
}

\section{EPIDEMIOLOGICAL ASPECTS OF SNAKEBITE ACCIDENTS REGISTERED IN THE STATE OF ACRE, BRAZIL, IN 2013-2017: AN ECOLOGICAL STUDY}

\author{
Oscar Nestor Condo Maqui \\ Mestre em Desenvolvimento Regional \\ Professor Substituto do Centro de Ciências Biológicas e da Natureza - CCBN \\ Universidade Federal do Acre - UFAC \\ nestor31174@hotmail.com \\ Priscila Araujo Melo \\ Mestranda em Saúde Coletiva \\ Universidade Federal do Acre - UFAC \\ priscilaa melo@outlook.com
}

\begin{abstract}
RESUMO
O presente estudo objetiva analisar os acidentes ofídicos ocorridos e notificados no Estado do Acre, Brasil, entre 2013 e 2017, a fim de colaborar com o planejamento estratégico das ações de saúde. Métodos: estudo epidemiológico, observacional, seccional, descritivo e retrospectivo. Foram utilizados dados obtidos nos registros de notificação do Sistema de informação de Agravos de Notificação - SINAN. Foram incluídos no estudo todos os casos de acidente ofídico notificados ao SINAN no Estado do Acre entre 2013 e 2017. Os dados coletados foram processados pelo Microsoft Excel 2016. Resultados: foram notificados 2.456 casos no período, com prevalência média de 491 casos/ano. A maior frequência foi em vítimas de cor parda $(81,15 \%)$, do sexo masculino $(72,35 \%)$. Os acidentes classificados como leves totalizaram $52,19 \%$; os que evoluíram com cura totalizaram $88,52 \%$. A maioria dos acidentes foi causada por serpentes do gênero Bothrops (63,19\%). Em 21,95\% dos casos o tempo decorrido entre o acidente e o atendimento foi de 0 a 1 hora. A frequência de acidentes foi maior nos meses do verão e outono. Considerações finais: Ainda existem falhas no fluxo de informação do SINAN. Houve equívoco no reconhecimento do gênero da serpente por parte da equipe de saúde no momento do atendimento. Situações como essa justificam a importância de treinamentos regulares para os profissionais envolvidos na linha de frente da assistência desse tipo de acidente. Serão necessários outros estudos de caráter social, ambiental e de saúde para responder a questões que ficaram abertas após as reflexões realizadas ao fim desta pesquisa.
\end{abstract}

Descritores: Acidente ofídico. Bothrops. Serpentes. Envenenamento.

\begin{abstract}
The present study aims to analyze the snake bite accidents that occurred and were reported in the State of Acre, Brazil, between 2013 and 2017, in order to collaborate with the strategic planning of health actions. Methods: epidemiological, observational, sectional, descriptive and retrospective study. Data obtained from the notification records of the Notifiable Diseases Information System - SINAN were used. All cases of snake bite reported to SINAN in the State of Acre between 2013 and 2017 were included in the study. The data collected were processed by Microsoft Excel 2016. Results: 2,456 cases were reported in the period, with an average prevalence of 491 cases / year. The highest frequency was in brown-colored victims
\end{abstract}

Recebido em: 23/03/2020

Aceito para publicação em: 03/08/2020. 
(81.15\%), male $(72.35 \%)$. Accidents classified as mild totaled $52.19 \%$; those who evolved with healing totaled $88.52 \%$. Most accidents were caused by Bothrops snakes $(63.19 \%)$. In $21.95 \%$ of cases, the time elapsed between the accident and the service was 0 to 1 hour. The frequency of accidents was higher in the summer and autumn months. Final considerations: There are still flaws in the information flow at SINAN. There was a mistake in the recognition of the serpent's gender by the health team at the time of care. Situations like this justify the importance of regular training for professionals involved in the front line of assistance for this type of accident. Further social, environmental and health studies will be needed to answer questions that remained open after the reflections made at the end of this research.

Descriptors: Snake bites. Bothrops. Snakes. Poisoning.

\section{INTRODUÇÃO}

Serpentes são encontradas em praticamente todo o mundo; seu habitat natural está nas regiões tropicais e temperadas, contudo, são capazes de adaptarem-se às mais distintas condições ecológicas (SANTOS et al., 2017). Um exemplo de onde achar esta heterogeneidade ecológica é na América Latina, região do continente americano, na qual o Brasil está localizado (BARBOSA, MEDEIROS, COSTA, 2015).

No Brasil, o bioma encontrado na Amazônia apresenta uma das mais ricas faunas de serpentes do mundo, contando com aproximadamente 140 espécies. Cerca de 40 espécies dentre estas são consideradas peçonhentas, constituindo uma emergência clínica frequente no país (VIEIRA e MACHADO, 2018; SILVA et al., 2019). É provável que, por essa razão, as mais elevadas taxas de acidentes ofídicos no Brasil tenham sido registradas, até o presente momento, na Amazônia (SILVA et al., 2019).

Serpentes peçonhentas são assim denominadas por sua capacidade de produzir veneno e armazenálo em glândulas que se comunicam com o exterior através de aparelhos especializados para inoculação no corpo da vítima. O veneno inoculado penetra na corrente sanguínea e age em diferentes órgãos e sistemas, afetando as funções fisiológicas, moleculares e celulares do corpo humano, podendo causar a morte do indivíduo acometido (BARBOSA, MEDEIROS, COSTA, 2015; JESUS et al., 2016; SILVEIRA e MACHADO, 2017; SILVA et al., 2017).

Os acidentes ofídicos costumam ser desencadeados pelo instinto de autodefesa das serpentes quando se sentem ameaçadas e "injuriadas" em seu habitat natural. Assim, não é rotineiro que elas ataquem sem uma injúria prévia (SANDRIN, PUORTO, NARDI, 2005; PARISE, 2016). Desta forma, está claro que a ocorrência destes acidentes aponta uma marcante relação com a sazonalidade, variações climáticas e ambientais do território, além do aumento das atividades humanas no campo (SANDRIN, PUORTO, NARDI, 2005; JESUS et al., 2016); esta última, implica em circulação humana em habitat natural das serpentes, desencadeando a injúria descrita anteriormente como sendo o "pivô" do ataque (BARBOSA, 2015; SANTANA e SUCHARA, 2015; GUIMARÃES, PALHA, SILVA, 2015; JESUS et al., 2016; SANTOS et al., 2017).

Os acidentes ofídicos representam, portanto, um sério problema de saúde pública, justificado por sua alta taxa de incidência e letalidade (SILVA et al., 2017; COSTA, 2018; SANTOS e NUNES, 2018; SILVA et al., 2019). São cerca de 20 mil casos registrados por ano no Brasil; um coeficiente médio de 13,8 casos/100 mil habitantes (COSTA, 2018). A variação regional é alarmante, com coeficientes três a quatro vezes maiores na região Norte, por exemplo (SANTANA e SUCHARA, 2015; SANTOS et al., 2017).

As espécies peçonhentas de interesse médico conhecidas no Brasil são classificadas em quatro grupos, de acordo com o gênero da serpente: (a) Botrópico (gênero Bothrops - jararacas); (b) Crotálico (gênero Crotalus - cascavéis); (c) Laquético (gênero Lachesis - surucucus); (d) Elapídico (gênero Micrurus - corais verdadeiras) (JESUS et al., 2016; CHEUNG e MACHADO, 2017; SANTOS et al., 2017; SILVEIRA e MACHADO, 2017; SILVA, et al., 2019). A média de casos anualmente registrados de acidentes ofídicos no Brasil obedece, de forma decrescente, à respectiva classificação dos grupos, sendo os acidentes causados por jararacas, os mais prevalentes $(86,23 \%$ dos casos) (JESUS et al., 
2016; SILVA et al., 2017), e os por corais verdadeiras, os menos prevalentes $(0,86 \%$ dos casos) (JESUS et al., 2016).

O alto percentual de acidentes atribuído ao gênero Bothrops é devido à elevada capacidade de adaptação destas serpentes (sinantropia) ao ecossistema tropical e pluviométrico. Entende-se que estas características são compatíveis com o que se encontra na região Amazônica (PARISE, 2016; SILVA et al., 2019), o que induz à inferência de que ataques por esta espécie possam ser frequentes nesta região brasileira.

A letalidade está associada principalmente às serpentes do gênero Crotalus, e/ou quando o protocolo de atendimento médico leva mais de seis horas para ser iniciado (em qualquer um dos gêneros) (PARISE, 2016).

Em relação ao gênero Micrurus, o tamanho diminuído de suas presas (típico em serpentes com hábitos de permanecer enterradas em buracos), justifica o baixo percentual de acidentes notificados (SILVA et al., 2019). O conhecimento dessa informação facilita a identificação (e/ou a exclusão) do gênero envolvido no ataque, ao levar-se em conta a área geográfica onde o acidente ocorreu (SILVEIRA e MACHADO, 2017).

Deste modo, é procedimento imprescindível na área médica, identificar o gênero da serpente causadora do ataque, uma vez que a identificação prévia e correta norteia a equipe hospitalar sobre os manejos precisos e imediatos a serem realizados em favor da vítima. A principal conduta é a infusão de um imunobiológico peculiar para anular o efeito nocivo do veneno: o soro antiofídico, o qual é específico para cada gênero (RITA, SISENANDO, MACHADO, 2016; LADEIRA e MACHADO, 2017; SANTOS et al., 2017; SILVA et al., 2017; SILVEIRA e MACHADO, 2017).

De fato, nem sempre é possível realizar a identificação da serpente. Por esta razão, analisar as manifestações clínicas do paciente e conhecer as taxas de frequência de ataque de cada gênero na região, antecipa o raciocínio clínico, o que aprimora a tomada de decisões por parte da equipe de saúde envolvida no atendimento da vítima (SANTOS et al., 2017; SILVA et al., 2019).

Cabe ressaltar que o retardo no tratamento adequado pode incrementar em custos elevados para os serviços de saúde, resultantes de internações prolongadas, sequelas graves, reabilitação e aposentadoria por invalidez (SANTANA e SUCHARA, 2015; SILVEIRA e MACHADO, 2017); todos estes agravantes são evitáveis, com o conhecimento adequado sobre a incidência, mortalidade e evolução dos casos (LADEIRA e MACHADO, 2017).

Reitera-se a relevância da epidemiologia no conhecimento do território e na identificação e caracterização da serpente envolvida em cada episódio (SILVEIRA e MACHADO, 2017; SILVA et al., 2019).

A ocorrência de acidentes ofídicos é considerada, desde 1986, de notificação compulsória (CHEUNG e MACHADO, 2017). A notificação é realizada pelo Sistema de Informação de Agravos de Notificação (SINAN) (SILVEIRA e MACHADO, 2017), criado em 1995 (VIEIRA e MACHADO, 2018), sendo o principal banco de dados da Coordenação Nacional de Controle e Zoonoses e Animais Peçonhentos (CNCZAP), do Ministério da Saúde (MS) (SILVEIRA e MACHADO, 2017). Os dados são disponibilizados para consulta pública online, desde 2006, referente às notificações realizadas a partir de 2001 (LADEIRA e MACHADO, 2017).

As informações contidas nestas notificações perfazem os elementos oficiais disponíveis a respeito desses agravos. A partir delas, é possível traçar um panorama do problema e, assim, promover reflexões que direcionem as ações de assistência adequadas à vítima e à população (SILVA et al., 2017).

O SINAN é, portanto, um sistema de informação de extrema relevância médica e epidemiológica. A avaliação da frequência das notificações de acidentes ofídicos norteia o MS na determinação de políticas de saúde, distribuição de imunobiológicos e treinamento das equipes de saúde (CHEUNG e MACHADO, 2017).

As publicações científicas contendo informações sobre o perfil epidemiológico dos acidentes ofídicos na Amazônia Ocidental (especialmente no Estado do Acre) são relativamente escassas; provavelmente por essa região não contar com uma estruturação ideal dos sistemas de informação, nem com serviços de saúde e de notificação de fácil acesso. Esta limitação abre margem para subnotificação de casos, o 
que "mascararia" a magnitude real das taxas de incidência nesta região (GUIMARÃES, PALHA, SILVA, 2015; COSTA, 2018).

Assim, o presente estudo objetiva analisar os casos de acidentes ofídicos ocorridos e notificados no Estado do Acre, Brasil, entre os anos 2013 e 2017. Esta análise propõe traçar um delineamento do perfil epidemiológico das ocorrências em função da época do ano, dos municípios mais acometidos, da proporção de envolvimento de cada gênero de serpente e da evolução final dos casos.

Logo, a finalidade deste artigo é colaborar com os bancos de dados científicos, fornecendo uma maior disponibilidade de dados a respeito desta temática, a fim de contribuir com a prática clínica, e auxiliar no planejamento estratégico das ações de saúde.

\section{MÉTODOS}

\section{Desenho}

Trata-se de um estudo epidemiológico, observacional, seccional, descritivo e retrospectivo, pautado em dados obtidos nos registros de notificação do SINAN, acessados online e gratuitamente via Sistema Datasus Tabnet Win 323.0 - "Acidentes por Animais Peçonhentos" (BRASIL, c2008).

Foram incluídos no estudo todos os casos de acidente ofídico notificados ao SINAN nos municípios do Estado do Acre. O período considerado neste estudo é relativo às notificações realizadas entre 2013 e 2017.

\section{População}

O Acre é um dos 27 estados brasileiros. Possui uma extensão territorial com superfície de 164.221,36 $\mathrm{km}^{2}$, correspondente a $4,26 \%$ da Região Norte e a $1,92 \%$ do território nacional. Está localizado no sudoeste da Região Norte, entre as latitudes de $-7^{\circ} 06^{\prime} 56 \mathrm{~N}$ e longitude $-73^{\circ} 48^{\prime} 05^{\prime \prime} \mathrm{N}$, latitude de $-11^{\circ}$ $08^{\prime} 41^{\prime \prime} \mathrm{S}$ e longitude $-68^{\circ} 42^{\prime} 59^{\prime \prime} \mathrm{S}$. Os limites do Acre estabelecem fronteiras internacionais com o Peru e Bolívia (BRASIL, 2018).

Os municípios desse Estado são, no total, 22, como expresso a seguir: Acrelândia, Assis Brasil, Brasileia, Bujari, Capixaba, Cruzeiro do Sul, Epitaciolândia, Feijó, Jordão, Manoel Urbano, Marechal Thaumaturgo, Mâncio Lima, Plácido de Castro, Porto Acre, Porto Walter, Rio Branco (capital), Rodrigues Alves, Santa Rosa do Purus, Sena Madureira, Senador Guiomard, Tarauacá e Xapuri (BRASIL, 2018).

Segundo o IBGE (c2017), a população do último censo (realizado em 2010) era de 733.559 habitantes, densidade demográfica de 4,47 habitantes $/ \mathrm{km}^{2}$; a população estimada para 2019 era de 881.935 habitantes.

\section{Análise estatística}

Foram analisadas as variáveis referentes: (a) às vítimas (raça e sexo); (b) ao gênero de serpente envolvida; (c) ao acidente (mês, ano, município onde ocorreu, tempo decorrido entre a picada e o atendimento, classificação - leve, moderado ou grave - e evolução final do caso).

Os critérios de inclusão abarcaram: acidente ofídico ocorrido dentro do território acreano entre 20132017; acidente notificado ao SINAN.

Os dados coletados foram armazenados em planilhas do software Microsoft Excel 2016. As tabelas e gráficos também foram elaborados com o auxílio deste software, após tratamento estatístico, por meio de análise uni e bivariada.

Para medir as taxas de incidência e prevalência foram empregadas as estimativas populacionais obtidas pelo Instituto Brasileiro de Geografia e Estatística (IBGE), através do Censo Demográfico realizado em 2010 (IBGE, c2017), acessado através do site do IBGE.

\section{Aspectos éticos}

Este estudo fez uso de dados secundários de domínio público. Não houve acesso a qualquer informação que estabelecesse identificação do paciente. Assim, com base legal, este estudo está dispensado de apreciação pelo Sistema CEP-CONEP, conforme preconiza a Resolução 466/2012 do Conselho Nacional de Saúde. 


\section{RESULTADOS}

O número total de casos notificados no período estudado foi de 2.456 casos, com prevalência média de 491 casos/ano no Estado do Acre. O município com maior frequência absoluta foi Rio Branco, capital, com um total de 611 casos no período. No entanto, o município com maior índice de prevalência foi Porto Walter, com taxa de 11 casos/1.000 habitantes, contra 1,8 casos/1.000 habitantes em Rio Branco. O ano que apresentou maior frequência de casos no período estudado foi 2015 ( $N=535)$. (Tabela 1)

Tabela 1 - Caracterização dos acidentes ofídicos no Estado do Acre, Brasil, entre 2013-2017

\begin{tabular}{|c|c|c|c|c|c|c|c|}
\hline \multicolumn{8}{|c|}{ Frequência de acidentes ofídicos } \\
\hline & 2013 & 2014 & 2015 & 2016 & 2017 & TOTAL & $\begin{array}{c}\text { Prevalência / mil } \\
\text { hab }\end{array}$ \\
\hline \multicolumn{8}{|c|}{ CIDADE } \\
\hline Acrelândia & 25 & 24 & 26 & 17 & 14 & 106 & 8,45 \\
\hline Assis Brasil & 6 & 8 & 3 & 4 & 9 & 30 & 4,94 \\
\hline Brasileia & 20 & 17 & 15 & 11 & 9 & 72 & 3,36 \\
\hline Bujari & 11 & 12 & 13 & 5 & 6 & 47 & 5,55 \\
\hline Capixaba & 4 & 6 & 3 & 5 & 2 & 20 & 2,27 \\
\hline Cruzeiro do Sul & 94 & 91 & 83 & 103 & 73 & 444 & 5,66 \\
\hline Epitaciolândia & 7 & 10 & 3 & 7 & 5 & 32 & 2,12 \\
\hline Feijó & 18 & 7 & 16 & 7 & 9 & 57 & 1,76 \\
\hline Jordão & 13 & 8 & 14 & 14 & 18 & 67 & 10,19 \\
\hline Manoel Urbano & 8 & 10 & 16 & 11 & 17 & 62 & 7,77 \\
\hline Marechal Thaumaturgo & 14 & 23 & 27 & 18 & 20 & 102 & 7,17 \\
\hline Mâncio Lima & 10 & 16 & 22 & 20 & 23 & 91 & 5,98 \\
\hline Plácido de Castro & 13 & 7 & 20 & 12 & 15 & 67 & 3,89 \\
\hline Porto Acre & 17 & 20 & 17 & 8 & 4 & 66 & 4,44 \\
\hline Porto Walter & 15 & 25 & 17 & 20 & 25 & 102 & 11,12 \\
\hline Rio Branco (capital) & 137 & 117 & 133 & 111 & 113 & 611 & 1,82 \\
\hline Rodrigues Alves & 16 & 12 & 17 & 23 & 16 & 84 & 5,84 \\
\hline Santa Rosa do Purus & 4 & 2 & 3 & 7 & 2 & 18 & 3,84 \\
\hline Sena Madureira & 23 & 46 & 37 & 24 & 30 & 160 & 4,21 \\
\hline Senador Guiomard & 11 & 7 & 5 & 1 & 5 & 29 & 1,44 \\
\hline Tarauacá & 15 & 19 & 25 & 33 & 24 & 116 & 3,26 \\
\hline Xapuri & 10 & 12 & 20 & 16 & 15 & 73 & 4,54 \\
\hline \multirow[t]{2}{*}{ Total } & 491 & 499 & 535 & 477 & 454 & 2.456 & 3,35 \\
\hline & \multicolumn{3}{|c|}{ RAÇA } & & & & \\
\hline Branca & 33 & 29 & 31 & 28 & 35 & 156 & \\
\hline Preta & 16 & 22 & 26 & 16 & 15 & 95 & \\
\hline Amarela & 5 & 0 & 2 & 0 & 1 & 8 & \\
\hline Parda & 384 & 406 & 438 & 398 & 367 & 1993 & \\
\hline Indígena & 25 & 22 & 19 & 18 & 23 & 107 & \\
\hline \multirow[t]{2}{*}{ Ignorada / em branco } & 28 & 20 & 19 & 17 & 13 & 97 & \\
\hline & \multicolumn{3}{|c|}{ SEXO } & & & & \\
\hline Feminino & 127 & 114 & 138 & 109 & 119 & 607 & \\
\hline Masculino & 344 & 368 & 382 & 357 & 326 & 1777 & \\
\hline Ignorado / em branco & 20 & 17 & 15 & 11 & 9 & 72 & \\
\hline
\end{tabular}

Fonte: o próprio autor 
Quanto à raça, as vítimas de cor parda apresentaram maior prevalência $(81,15 \%)(\mathrm{N}=1.993)$. Quanto ao sexo, a maior frequência de casos foi observada no sexo masculino $(72,35 \%)(\mathrm{N}=1.777)$. (Tabela 1$)$

A respeito do gênero da serpente, verificou-se que $63,19 \%$ dos casos notificados $(\mathrm{N}=1.552)$ foram do gênero Bothrops, seguido pelo gênero Lachesis $(13,97 \%)(\mathrm{N}=343)$, espécies não peçonhentas $(3,5 \%)$ $(\mathrm{N}=86)$, Crotalus $(0,61 \%)(\mathrm{N}=15)$ e Micrurus $(0,49 \%)(\mathrm{N}=12)$. Do total de casos, houve $448(18,24 \%)$ preenchidos como "ignorado / em branco". (Tabela 2 e Gráfico 1)

Tabela 2 - Caracterização clínica dos acidentes ofídicos no Estado do Acre, Brasil, entre 2013-2017

\begin{tabular}{|c|c|c|c|c|c|c|c|}
\hline \multirow[b]{3}{*}{ GÊNERO DA SERPENTE } & \multicolumn{6}{|c|}{ Frequência de acidentes ofídicos } & \multirow[b]{2}{*}{$\%$} \\
\hline & 2013 & 2014 & 2015 & 2016 & 2017 & TOTAL & \\
\hline & & & & & & & \\
\hline Bothrops & 282 & 284 & 342 & 324 & 320 & 1552 & 63,19 \\
\hline Crotalus & 0 & 4 & 3 & 5 & 3 & 15 & 0,61 \\
\hline Lachesis & 91 & 98 & 70 & 48 & 36 & 343 & 13,97 \\
\hline Micrurus & 1 & 2 & 3 & 2 & 4 & 12 & 0,49 \\
\hline Não peçonhento & 9 & 17 & 23 & 23 & 14 & 86 & 3,5 \\
\hline Ignorado / em branco & 108 & 94 & 94 & 75 & 77 & 448 & 18,24 \\
\hline \multicolumn{8}{|c|}{ CLASSIFICAÇÃO DO ACIDENTE } \\
\hline Leve & 260 & 254 & 281 & 246 & 240 & 1281 & 52,16 \\
\hline Moderado & 165 & 180 & 185 & 171 & 165 & 866 & 35,26 \\
\hline Grave & 21 & 15 & 34 & 33 & 25 & 128 & 5,21 \\
\hline Inconclusivo & 0 & 0 & 0 & 0 & 0 & 0 & 0 \\
\hline Ignorado / em branco & 45 & 50 & 35 & 27 & 24 & 181 & 7,37 \\
\hline \multicolumn{8}{|c|}{ TEMPO DECORRIDO ENTRE A PICADA E O ATENDIMENTO } \\
\hline 0 a 1 hora & 104 & 104 & 136 & 93 & 102 & 539 & 21,95 \\
\hline 1 a 3 horas & 78 & 111 & 124 & 123 & 123 & 559 & 22,76 \\
\hline 3 a 6 horas & 106 & 97 & 102 & 113 & 76 & 494 & 20,11 \\
\hline 6 a 12 horas & 26 & 44 & 43 & 26 & 42 & 181 & 7,37 \\
\hline 12 a 24 horas & 71 & 50 & 29 & 30 & 30 & 210 & 8,55 \\
\hline$>$ de 24 horas & 64 & 56 & 58 & 48 & 51 & 277 & 11,28 \\
\hline Ignorado / em branco & 42 & 37 & 43 & 44 & 30 & 196 & 7,98 \\
\hline \multicolumn{8}{|l|}{ EVOLUÇÃO FINAL } \\
\hline Cura & 416 & 421 & 486 & 440 & 411 & 2174 & 88,52 \\
\hline Óbito pelo agravo & 3 & 0 & 1 & 2 & 1 & 7 & 0,29 \\
\hline Óbito por outra causa & 1 & 0 & 0 & 0 & 0 & 1 & 0,04 \\
\hline Óbito em investigação & 0 & 0 & 0 & 0 & 0 & 0 & 0,00 \\
\hline Ignorado / em branco & 71 & 78 & 48 & 35 & 42 & 274 & 11,16 \\
\hline
\end{tabular}

Fonte: o próprio autor 
Gráfico 1 - Gênero da serpente envolvida nos acidentes ofídicos registrados no Estado do Acre, Brasil, entre 2013-2017

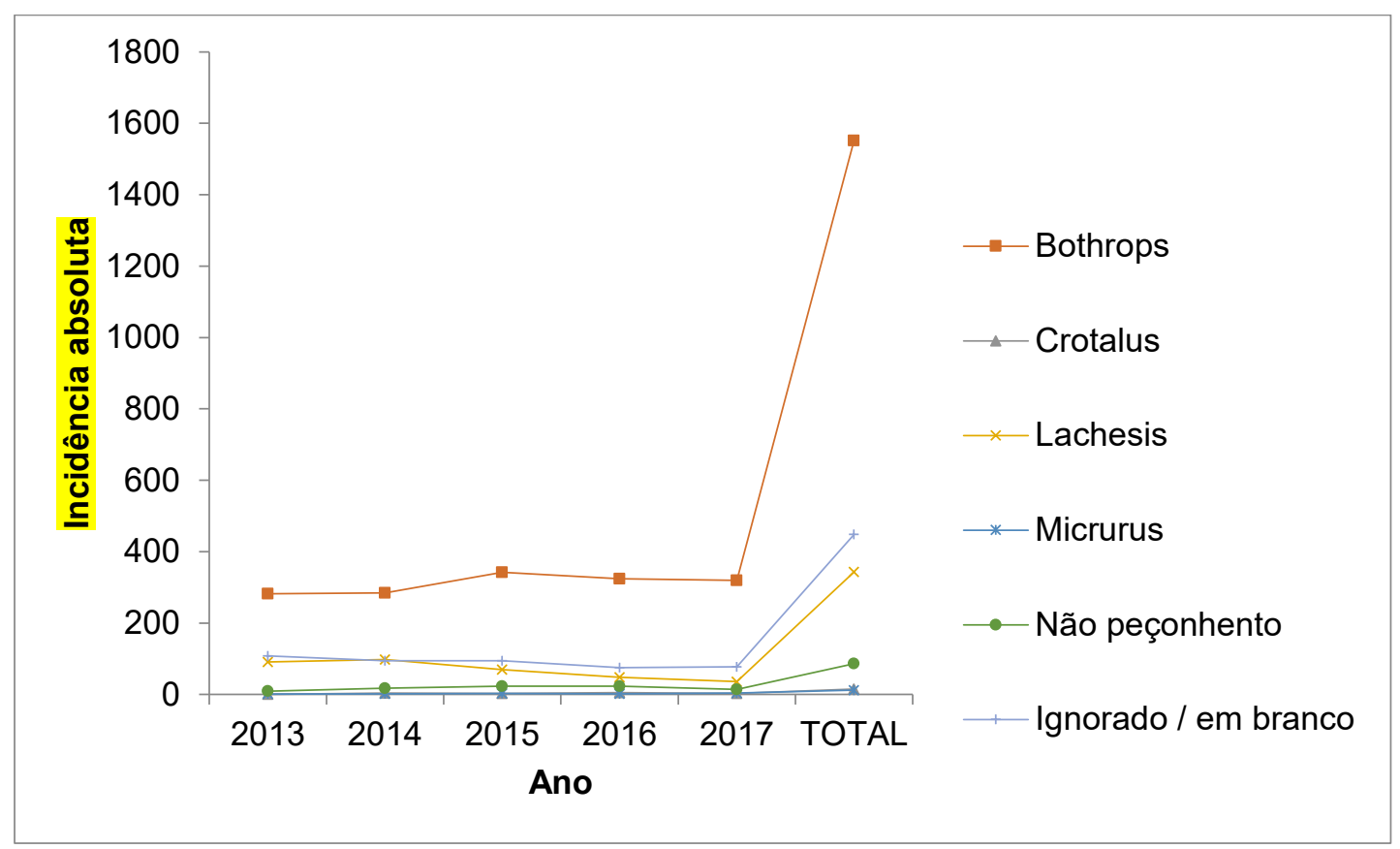

Fonte: o próprio autor

Quanto à classificação do acidente, a maioria dos casos foi considerada como leve $(52,16 \%)(\mathrm{N}=1.281)$. Do total de casos, $88,52 \%(\mathrm{~N}=2.174)$ evoluíram com cura, $0,29 \%(\mathrm{~N}=7)$ resultaram em óbito pelo agravo e $0,04 \%(N=1)$ resultaram em óbito por outra causa. (Tabela 2 e Gráfico 2$)$

Gráfico 2 - Classificação dos acidentes ofídicos registrados no Estado do Acre, Brasil, entre 20132017

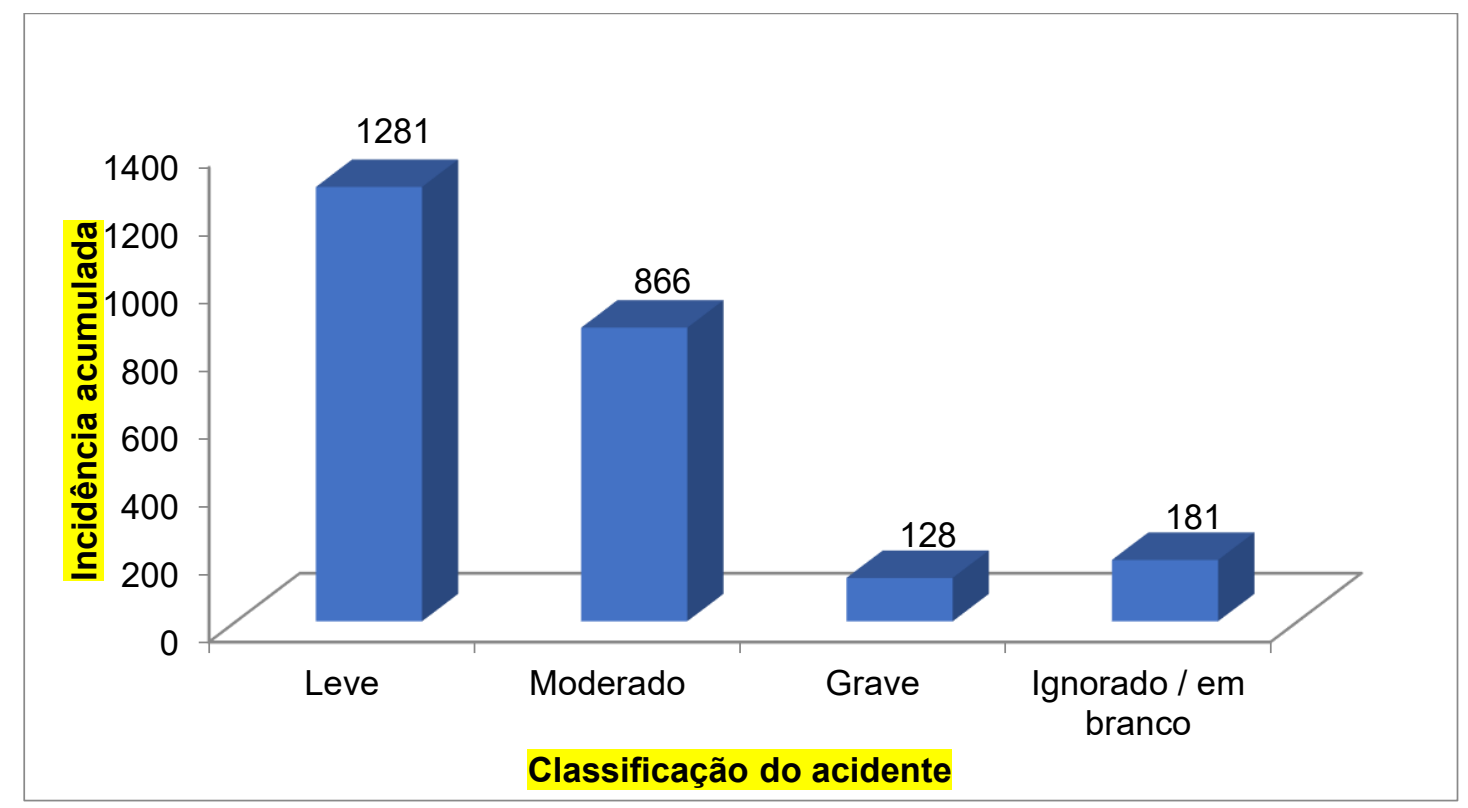

Fonte: o próprio autor 
Quanto ao período sazonal de ocorrência, os meses que apresentaram frequência acima da média (> 200 casos / mês) foram: janeiro, fevereiro, março, abril, maio, novembro e dezembro. Do total de casos, $15,73 \%$ foram preenchidos como "ignorado / em branco" (Gráfico 3). Além disso, o quantitativo computado na pesquisa quanto ao mês de ocorrência não coincidiu com o quantitativo geral anteriormente descrito $(\mathrm{N}=2.456)$. Nesta pesquisa, foram computados 2.389 casos.

Gráfico 3 - Distribuição dos acidentes ofídicos registrados no Estado do Acre, Brasil, entre 2013-2017, segundo os meses do ano

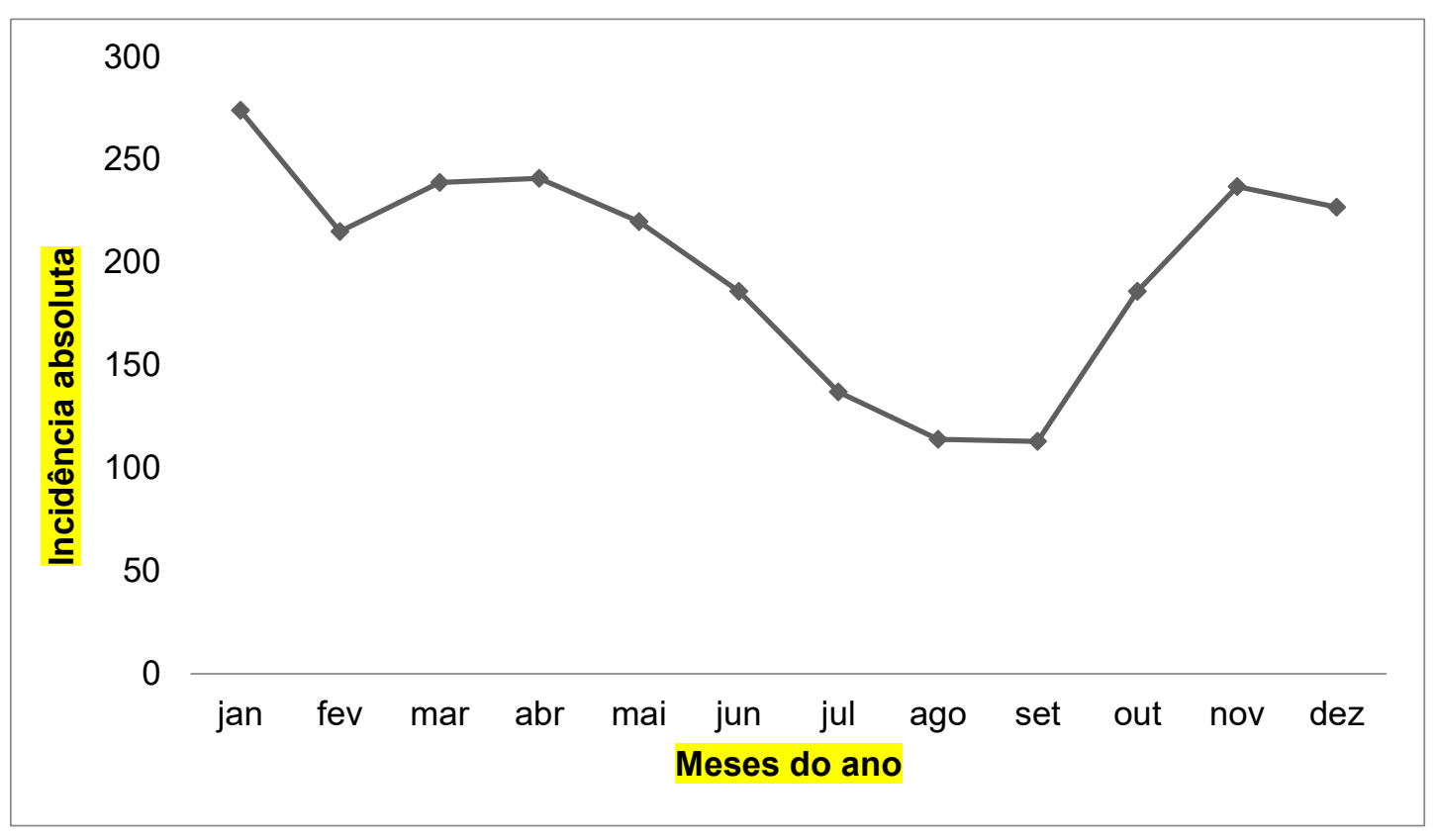

Fonte: o próprio autor

\section{DISCUSSÃO}

Desde 2009, a Organização Mundial da Saúde (OMS) e a Academia Brasileira de Ciências consideram os acidentes ofídicos como "doenças tropicais negligenciadas" (DTN) (CHEUNG e MACHADO, 2017; SANTOS e NUNES, 2018; VIEIRA e MACHADO, 2018; SILVA et al., 2019), as quais são doenças que já foram total ou parcialmente erradicadas em países desenvolvidos, no entanto, persistem em países subdesenvolvidos (CHEUNG e MACHADO, 2017). A população mais vulnerável - tanto nos países desenvolvidos quanto nos subdesenvolvidos - é a de trabalhadores rurais, que normalmente residem em localidades relativamente isoladas e afastadas dos centros (SILVA et al., 2019).

Segundo o Ministério da Saúde (BRASIL, 2008), através de dados obtidos no Sinan Net, no Brasil ocorreu 119.555 acidentes ofídicos notificados no período entre 2013-2017, incluindo serpentes não peçonhentas e excluindo as notificações cuja espécie da serpente não fora identificada; uma média de 23.911 casos/ano. Os acidentes ocorridos no Estado do Acre representaram, nesse período, cerca de $2 \%$ do total de acidentes notificados. No entanto, pesquisadores apontam que é na Amazônia onde ocorre a maior prevalência desses acidentes, por ser esta uma região com características geográficas, de condição climática e de fauna que favorecem essa elevada ocorrência. Associado a isso, o perfil econômico da região Norte também é um fator favorável aos acidentes ofídicos, uma vez que nesta região predomina a atividade extrativista, de caça e pesca, propiciando uma maior exposição da população à fauna, logo, às serpentes (MORENO et al., 2005; LIMA, CAMPOS, RIBEIRO, 2009; SANTOS et al., 2017). Assim, é coerente considerar a possibilidade de que possa haver um alto índice de subnotificação nesta região.

Quanto ao gênero mais acometido, os homens são as principais vítimas de acidentes ofídicos (BOCHNER, STRUCHNER, 2003; SANTOS et al., 2017). Tal informação é compatível com os resultados desta pesquisa. Há, ainda, pesquisadores que defendem que o gênero masculino reforça

DOI: http://dx.doi.org/10.14393/Hygeia16053321 $\quad$ Hygeia $\quad$ v.16 $\quad$ p.174-187, 2020 página 181


sua virilidade no ponto de vista de que são autossuficientes e, portanto, mais tendenciosos à negligência quanto às medidas de prevenção. Por esta razão, tornam-se mais vulneráveis ao ataque das serpentes (SANTOS et al., 2017).

A respeito da raça, o alto percentual de acidentes ofídicos ocorridos com vítimas de cor parda levanta um questionamento pertinente: Qual fator justifica a elevada incidência de casos com esses indivíduos? Seria pela característica étnico-racial da população do Estado do Acre ou poderia haver uma predileção das serpentes por vítimas dessa raça? Segundo o IBGE (c2017), a população de indivíduos de cor parda aferida no Censo Demográfico de 2010 era de 486.254 habitantes, o equivalente a $66,29 \%$ da população total do Estado do Acre neste mesmo período. É razoável conjeturar que o aumento na incidência de acidentes ofídicos seja justificado pelo percentual de indivíduos de cor parda no Estado do Acre.

Em relação ao tempo decorrido entre o momento da picada e o atendimento, notou-se que em $21,9 \%$ dos casos as vítimas foram atendidas em até 1 hora; este é o tempo ideal preconizado pelas autoridades de saúde. Embora o número de vítimas que buscaram socorro em menos de 1 hora não perfaça nem a metade dos casos, alguns tipos de acidentes ofídicos podem cursar sem complicação, caso o atendimento médico ocorra em até 3 horas (SILVEIRA, MACHADO, 2017). Nessa perspectiva, em $44,7 \%$ dos casos as vítimas foram atendidas em tempo hábil (de 0 a 3 horas).

Os relatos de estudos anteriores corroboram que os acidentes leves são os mais prevalentes (SANTOS et al., 2017). Essas informações evidenciadas são compatíveis com os resultados deste estudo. Segundo o Ministério da Saúde (2001), os critérios para classificação do tipo de acidente ofídico variam de acordo com as manifestações clínicas características do gênero de serpente envolvida (Tabela 3).

Os acidentes ofídicos causados pelo gênero Bothrops, no Brasil, tem maior relevância, equivalendo a mais de $90 \%$ dos casos registrados; resultado parecido com o aferido neste estudo $(63,19 \%)$. Tamanho percentual pode estar relacionado com o comportamento destas serpentes, as quais permanecem entrelaçadas e/ou camufladas por entre as folhas durante o dia; habitam principalmente na zona rural e possuem hábitos predominantemente noturnos (SANTOS et al., 2017; SILVA et al., 2019). Além destes fatores, cabe incluir também a morfologia do aparelho inoculador deste gênero de serpente: consiste num aparelho especializado, constituído por dentes posicionados anteriormente à cavidade bucal e perpendicularmente ao palato quando a boca da serpente está fechada; este aparelho se projeta para frente no momento do ataque ofídico (CUNHA, MARTINS, 2012).A dentição é do tipo solenoglifodonte, a qual consiste num par de dentes maxilares modificados e adaptados para inocular o veneno; trata-se de um complexo mecanismo inoculador, o qual permite uma grande abertura bucal, facilitando o posicionamento dos dentes em relação à presa (SAKAl, 2011).

Como já mencionado neste trabalho, o soro antiofídico anula o efeito do veneno da serpente, portanto sendo o tratamento padrão ouro nos acidentes ofídicos. No Brasil, o soro antiofídico é produzido pelo Instituto Butantan, Instituto Vital Brasil e Fundação Ezequiel Dias; é oferecido gratuitamente às vítimas de acidente ofídico e disponibilizado aos hospitais de todo o território nacional através das secretarias de saúde (SANTOS et al., 2017). A eficácia do soro é tão elevada - haja vista que a administração precoce neutraliza a atividade do veneno -, que os casos que evoluíram como graves neste estudo são aqueles cujo tempo decorrido desde o acidente até o socorro foi superior a 3 horas, sugerindo que o atendimento tardio repercutiu em mau prognóstico dos pacientes. Para Albuquerque et al. (2013), o longo intervalo entre o acidente e o atendimento culmina em um quadro clínico mais grave. Segundo Moreno et al. (2005), o tratamento com o soro adequado e na maior brevidade possível evita complicações orgânicas, sobretudo aquelas causadas por serpentes cujo veneno possui ação neurotóxica (afeta diretamente o sistema nervoso).

Quando analisado o total de acidentes registrados no período, verificou-se que a variação da incidência anual não seguiu uma tendência definida, isto é, não houve um padrão de crescimento ou decréscimo percebido em função do decorrer dos anos. 
Tabela 3 - Caracterização do tipo de acidente ofídico, segundo as manifestações clínicas típicas do quadro clínico das vítimas

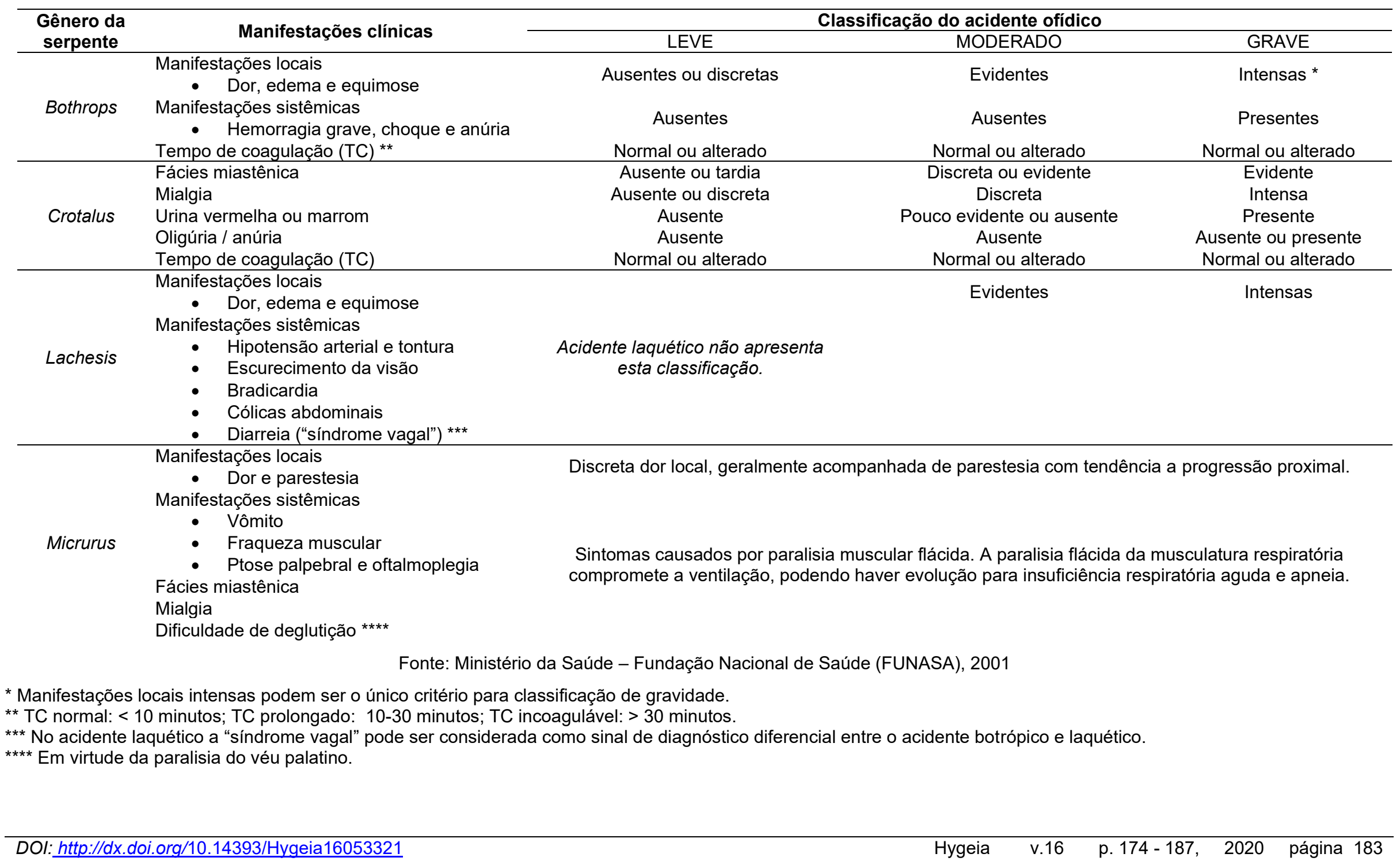


Quando analisado o total de acidentes em função dos meses do ano, percebeu-se que os meses com prevalência anual acima da média dizem respeito a duas estações do ano: o verão e outono.

Segundo o Centro de Previsão de Tempo e Estudos Climáticos - CPTEC (c2020), o verão se inicia no final de dezembro e termina em março. Nessa estação ocorrem mudanças bruscas nas condições diárias do tempo, levando à ocorrência de chuvas de curta duração e forte intensidade. O outono se inicia no final de março, perdurando até junho. É também uma estação onde se verifica mudanças rápidas nas condições do tempo, com registro dos maiores totais de chuva (superior a $700 \mathrm{~mm}$ ) na região Norte e Nordeste do Brasil.

O elevado índice pluviométrico induz o agropecuarista - tanto o profissional quanto o de subsistência - e demais trabalhadores rurais a se envolver com maior avidez nas atividades extrativistas nessas estações de forte expressão pecuarista. De certo, esta medida expõe ainda mais estes trabalhadores a serem as vítimas mais frequentes dos acidentes ofídicos (SILVA et al., 2019).

Serpentes são encontradas com maior facilidade em estações cuja temperatura é relativamente elevada, devido à pecilotermia (estado em que a temperatura corporal varia de acordo com o ambiente). Por essa razão, no inverno as serpentes tendem a hibernar, ato instintivo para se proteger das baixas temperaturas (SILVA et al., 2019). Apesar disto, deve ser levado em conta que, segundo a Classificação Climática de Köppen-Geiger, o Estado do Acre apresenta condição climática do tipo Af (equatorial ou tropical úmido), o que tornaria o cenário de hibernação menos provável (PEEL, FINLAYSON, MCMAHON, 2007; SANTOS, FERREIRA, 2013). Nesse contexto, é relevante investigar se há risco relativo para acidente ofídico que seja atribuível às condições climáticas (pluviosidade e temperatura) como fator causal.

Houve algumas limitações na execução desta pesquisa, as quais prejudicaram a acurácia dos resultados levantados. Cabe mencionar como principal limitação os dados subnotificados junto ao SINAN, o que mascara a real magnitude da problemática levantada neste artigo - o panorama dos acidentes ofídicos ocorridos no Estado do Acre. Na coleta de dados deste estudo não houve evidências de subnotificação de casos. Entretanto, ficou evidenciada a subnotificação de dados. Este fenômeno foi observado durante a coleta de dados. Ao consultar o total de casos de acidente ofídico utilizando o filtro "mês", não houve congruência com o quantitativo de casos a consulta do quantitativo de casos globais no mesmo período. Além dos dados subnotificados, foi grande o número de dados preenchidos como "ignorados / em branco".

Houve, ainda, uma divergência importante entre os dados preenchidos nas Fichas Individuais de Notificação (FIN) do SINAN desta pesquisa e o referencial teórico, pois, segundo Bernarde e Gomes (2012), no Acre não há registro de espécies do gênero Crotalus; ainda assim, foram registrados 15 casos de acidentes crotálicos no período de 2013 a 2017.

\section{CONSIDERAÇÕES FINAIS}

Os acidentes ofídicos representam um importante problema de saúde pública. Os homens foram as principais vítimas em relação às mulheres. Quanto ao gênero da serpente, prevaleceu o Bothrops. A maior prevalência foi de casos leves, cuja evolução cursou com cura.

Os dados mostraram que ainda existem falhas no fluxo de informação do SINAN, e que o grande número de informações preenchidas como "ignorado / em branco" dificulta a obtenção de dados fidedignos. Por isso, notou-se a importância da adoção de medidas para que o preenchimento das FIN seja realizado de forma que contemple o maior arsenal possível de informações e, assim, evite as limitações que possam atrapalhar a aferição adequada de dados em estudos futuros.

Entre essas medidas, deve-se priorizar o interesse do médico e da equipe de saúde que atendem a vítima de acidente ofídico em preencher a FIN; sabe-se que essa ficha contém muitas informações, e, na maioria dos hospitais, as altas demandas cotidianas do plantão põem, inevitavelmente, o preenchimento de documentos em segundo plano (o preenchimento da FIN é visto como burocrático e trabalhoso). Assim, é irrefutável a concepção de que o preenchimento cuidado deste documento exige um tempo maior do que aquele "disponível" na assistência.

Por esta razão, é útil considerar como coadjuvante o preenchimento online da FIN, o qual pode otimizar o tempo empregado na notificação - completa - do acidente. Outra medida que pode auxiliar consiste no desenvolvimento de testes rápidos para identificação do gênero da serpente a partir do sangue da

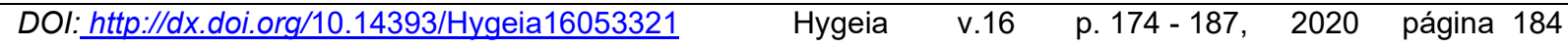


vítima, ao compreendermos que as manifestações clínicas das diferentes espécies de serpente podem ser semelhantes entre si e acabem atuando como fatores confundidores na tomada de decisão médica. O desenvolvimento destes testes rápidos ainda não passa de uma ideia, e caso seja, de fato, concretizada, oferecerá uma contribuição de impacto para a prática clínica.

Estudos futuros serão necessários para avaliar o impacto que a adoção de tais medidas possa ter trazido à população. É esperado que a adoção dessas medidas contribua positivamente para o desfecho do caso e prognóstico da vítima, uma vez que se sabe a importância da agilidade na tomada de decisões médicas, pois o tempo decorrido entre o acidente e o atendimento pode ser decisivo na cura da vítima.

Serão necessários outros estudos de caráter social, ambiental e de saúde -preferencialmente com a base populacional que compôs esta pesquisa - para investigar os fatores que propiciaram: o acidente, o retardo na busca por atendimento médico, as evoluções finais com mau prognóstico, horário do acidente, etc.

Como discorrido nas limitações do trabalho, foi observado o registro de quinze casos de acidente pelo gênero Crotalus, quando, na realidade, sabidamente não há ocorrência de espécies deste gênero. Conclui-se que houve equívoco no reconhecimento do gênero da serpente por parte da equipe de saúde no momento do atendimento. Situações como essa são frequentes e justificam a importância de treinamentos regulares para os profissionais envolvidos na linha de frente junto à assistência desse tipo de acidente.

\section{REFERÊNCIAS}

ALBUQUERQUE, PLMM et al. Perfil epidemiológico dos acidentes por picada de cobra em Região Metropolitana do Nordeste do Brasil. Rev. Inst. Med. Trop. São Paulo. 2013; 55, 347-351.

BARBOSA, IR. Aspectos clínicos e epidemiológicos dos acidentes provocados por animais peçonhentos no estado do Rio Grande do Norte. Revista Ciência Plural. 2015; 1(3):02-13.

BARBOSA, IR.; MEDEIROS, WR.; COSTA, ICC. Distribuição espacial dos acidentes por animais peçonhentos no estado do Rio Grande do Norte - Brasil no período de 2001-2010. Caminhos de Geografia, Uberlândia. 2015 Mar; 16(53):55-64.

BERNARDE, PC.; GOMES, JO. Serpentes peçonhentas e ofidismo em Cruzeiro do Sul, Alto Juruá, Estado do Acre, Brasil. Acta Amazonica. 2012; 42(1):65-72. https://doi.org/10.1590/S0044$\underline{59672012000100008}$

BOCHNER, R.; STRUCHNER, CJ. Epidemiologia dos acidentes ofídicos nos últimos 100 anos no Brasil: uma revisão. Cad Saúde Pública. 2003; 19(1): 7-16. https://doi.org/10.1590/S0102$\underline{311 \times 2003000100002}$

BRASIL. Governo do Acre. Acre. Disponível em: <http://acre.gov.br/acre/>. Acesso em: 12 ago. 2019.

BRASIL. Ministério da Saúde. DATASUS - Departamento de Informática do SUS. Portal da Saúde Informações de Saúde Tabnet: Doenças e Agravos de Notificação - de 2007 em diante (SINAN). Disponivel em: <http://www2.datasus.gov.br/DATASUS/index.php?area=0203\&id=29878153>. Acesso em: 12 ago. 2019. Copyright 2008.

BRASIL. Ministério da Saúde. FUNASA - Fundação Nacional de Saúde. Manual de Diagnóstico e Tratamento de Acidentes por Animais Peçonhentos. Brasília. Ministério da Saúde: Secretaria de Vigilância Epidemiológica, 2001.

CHEUNG, R.; MACHADO, C. Acidentes por animais peçonhentos na região dos Lagos, Rio de Janeiro, Brasil. Journal Health NPEPS. 2017; 2(Supl.1):73-87.

COSTA, MMR. et al. Acidentes ofídicos: perfil epidemiológico na mesorregião do sertão Pernambucano, Brasil. Braz. J. Hea. Rev., Curitiba. 2018 Jul-Set; 1(1):245-251.

CPTEC - CENTRO DE PREVISÃO DE TEMPO E ESTUDOS CLIMÁTICOS. Estações do ano. Disponível em: <https://clima1.cptec.inpe.br/estacoes/>. Acesso em: 08 mar. 2020. Copyright 19952020. 
CUNHA, EM.; MARTINS, OA. Principais compostos químicos presentes nos venenos de cobras do gênero Bothrops e Crotalus - uma revisão. Revista Eletrônica de Educação e Ciência, Avaré. 2012; 2(2):21-26.

GUIMARÃES, CDO.; PALHA, MC.; SILVA, JCR. Perfil clínico-epidemiológico dos acidentes ofídicos ocorridos na ilha de Colares, Pará, Amazônia Oriental. Semina: Ciências Biológicas e da Saúde, Londrina. 2015 Jan-Jun; 36(1):67-78. https://doi.org/10.5433/1679-0367.2015v36n1p67

IBGE - INSTITUTO BRASILEIRO DE GEOGRAFIA E ESTATÍSTICA. Censo demográfico: Panorama no Estado do Acre. Disponível em: <https://cidades.ibge.gov.br/brasil/ac/panorama>. Acesso em 12 ago. 2019. Copyright 2017.

IBGE - INSTITUTO BRASILEIRO DE GEOGRAFIA E ESTATÍSTICA. Censo demográfico. Tabela 3175 - População residente, por cor ou raça, segundo a situação do domicílio, o sexo e a idade. Disponível em: < https://sidra.ibge.gov.br/Tabela/3175>. Acesso em 20 jul. 2020. Copyright 2017.

JESUS, AG.; GOMES, H.; BARASUOL, AM.; VIEIRA, GDS.; SOUSA, ERM. Avaliação dos acidentes ofídicios na região sob influência da Usina Hidelétrica Belo Monte - Estado do Pará. Revista Cereus. 2016 Set-Dez; 8(3):02-18. https://doi.org/10.18605/2175-7275/cereus.v8n3p2-18

LADEIRA, CGP.; MACHADO, C. Epidemiologia dos acidentes com animais peçonhentos na região de Ponte Nova, Minas Gerais, Brasil. Journal Health NPEPS. 2017; 2(Supl.1):40-57.

LIMA, ACSF.; CAMPOS, CEC.; RIBEIRO, JR. Perfil epidemiológico de acidentes ofídicos do Estado do Amapá. Revista da Sociedade Brasileira de Medicina Tropical. 2009 Mai-jun; 42(3):329335. https://doi.org/10.1590/S0037-86822009000300017

MORENO, E.; ANDRADE, MQ.; SILVA, RML.; TAVARES, JN. Características clínicoepidemiológicas dos acidentes ofídicos em Rio Branco, Acre. Revista da Sociedade Brasileira de Medicina Tropical, Rio Branco. 2005; 38(1):15-21. https://doi.org/10.1590/S0037-86822005000100004

PARISE, EV. Vigilância e monitoramento dos acidentes por animais peçonhentos no município de Palmas, Tocantins, Brasil. Hygeia. 2016 Jun; 12(22):72-87.

PEEL, MC.; FINLAYSON, BL.; MCMAHON, TA. Updated world map of the Koppen-Geiger climate classification. Hydrol. Earth Syst. Sci. 2007; 11:1633-1644. https://doi.org/10.5194/hess-11-1633$\underline{2007}$

RITA, TS.; SISENANDO, HA.; MACHADO, C. Análise epidemiológica dos acidentes ofídicos no município de Teresópolis - RJ no período de 2007 a 2010. Revista Ciência Plural. 2016; 2(2):28-41.

SAKAI, F. Glândula acessória e ducto primário de serpente Bothrops jararaca durante o ciclo de produção de veneno: um estudo morfológico. Dissertação (Mestrado) - Universidade São Paulo USP. São Paulo, 2011.

SANDRIN, MFN.; PUORTO, G.; NARDI, R. Serpentes e acidentes ofídicos: um estudo sobre erros conceituais em livros didáticos. Investigações em Ensino de Ciências. 2005; 10(3):281-298.

SANTANA, VTP.; SUCHARA, EA. Epidemiologia dos acidentes com animais peçonhentos registrados em Nova Xavantina - MT. Rev Epidemiol Control Infect. 2015; 5(3):141-146. https://doi.org/10.17058/reci.v5i3.5724

SANTOS, AA.; VIZOTTO, RM.; SOUZA, LP.; LIMA, MG.; VIANA, TC. Perfil clínico-epidemiológico dos pacientes vítimas de acidentes ofídicos no município de Cacoal, Rondônia, Brasil, no período de 2009 a 2013. J Health Biol Sci. 2017 Jul-Set; 5(3):221-227. https://doi.org/10.12662/23173076jhbs.v5i3.1275.p221-227.2017

SANTOS, AV.; NUNES, ALBP.; NUNES, DCOS. Epidemiologia dos acidentes causados por animais peçonhentos no município de Patrocínio (MG), Brasil (2015-2017). Hygeia. 2018 Dez; 14(30):82-94.

SANTOS, LR.; SANTOS, EA.; FERREIRA, EJL. Estimativa da capacidade de estoque de biomassa e carbono da vegetação arbórea de um fragmento do parque urbano Tucumã, em Rio Branco, Acre. Enciclopédia Biosfera. 2013; 9(17): 1305-1321.

SILVA, JH. et al. Perfil epidemiológico dos acidentes com animais peçonhentos em Tangará da Serra - MT, Brasil (2007-2016). Journal Health NPEPS. 2017; 2(Supl.1):05-15.

DOI: http://dx.doi.org/10.14393/Hygeia16053321 $\quad$ Hygeia $\quad$ v.16 $\quad$ p. $174-187,2020$ página 186


SILVA, MJC. et al. Perfil epidemiológico dos acidentes ofídicos da mesorregião do baixo Amazonas do estado do Pará, Brasil. Braz. J. Hea. Rev., Curitiba. 2019 Mar-Abr; 2(2):1968-1979.

SILVEIRA, JL.; MACHADO, C. Epidemiologia dos acidentes por animais peçonhentos nos municípios do Sul de Minas Gerais. Journal Health NPEPS. 2017; 2(Supl.1):88-101.

VIEIRA, GPS.; MACHADO, C. Acidentes por animais peçonhentos na região Serrana, Rio de Janeiro, Brasil. Journal Health NPEPS. 2018; 3(1):211-227. https://doi.org/10.30681/252610102776 